\title{
Teaching NeuroImages: Hopkins syndrome
}

\section{A rare differential diagnosis of neurogenic monomelic amyotrophy}

Paulo Victor Sgobbi de Souza, MD, Bruno de Mattos Lombardi Badia, MD, Eduardo Augusto Gonçalves, MD, Igor Braga Farias, MD, Luiz Henrique Libardi Silva, MD, Mario Teruo Yanagiura, MD,

Wladimir Bocca Vieira de Rezende Pinto, MD, MSc, and Acary Souza Bulle Oliveira, MD, PhD

Neurology ${ }^{\circledR}$ 2020;94:e996-e997. doi:10.1212/WNL.0000000000009038

Figure Neurologic examination of the lower limbs in Hopkins syndrome

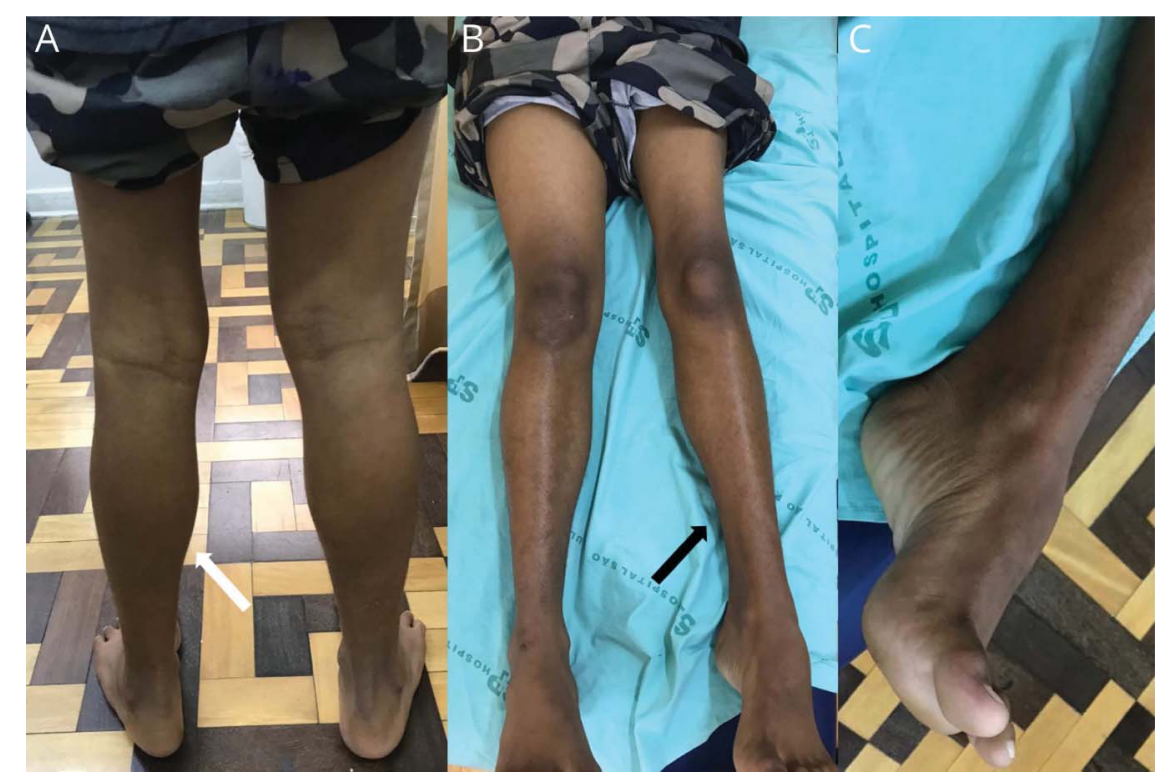

Marked monomelic amyotrophy involving proximal and distal portions the left lower limb (white and black arrows) $(A, B)$, including pes cavus and toe retraction in the left foot (C).

An 11-year-old Brazilian boy presented with worsening left thigh weakness. At age 2 years, he presented with left lower limb weakness after 4 days of a severe asthma episode. Examination showed amyotrophy, weakness, and areflexia of the left lower limb (figure). Spine MRI and CSF analysis (including serology and PCR for herpesvirus, enterovirus, and arbovirus) were unremarkable. Neurophysiologic studies exhibited ongoing denervation and chronic reinnervation changes involving the left lower limb muscle groups. Our patient was diagnosed with Hopkins syndrome, a rare childhood-onset lower motor neuron disease presenting with monomelic amyotrophy after an acute asthma attack. ${ }^{1,2}$

\section{Acknowledgment}

Full consent was obtained from the patient's parents for the case report and the study was approved by the authors' institutional ethics committee.

\section{Correspondence}

Dr. Bocca Vieira de Rezende Pinto

wladimirbvrpinto@

gmail.com

\section{Study funding}

No targeted funding reported.

\section{MORE ONLINE}

\section{$\rightarrow$ Teaching slides}

links.lww.com/WNL/

B48 


\section{Disclosure}

The authors report no disclosures relevant to the manuscript. Go to Neurology.org/N for full disclosures.

\section{Appendix Authors}

\begin{tabular}{|c|c|c|c|}
\hline Name & Location & Role & Contribution \\
\hline $\begin{array}{l}\text { Paulo Victor } \\
\text { Sgobbi de } \\
\text { Souza, MD }\end{array}$ & $\begin{array}{l}\text { Federal } \\
\text { University of } \\
\text { São Paulo } \\
\text { (UNIFESP), } \\
\text { Brazil }\end{array}$ & First author & $\begin{array}{l}\text { Case report project } \\
\text { (conception, } \\
\text { organization, } \\
\text { execution), writing } \\
\text { of the first draft, } \\
\text { review and critique }\end{array}$ \\
\hline $\begin{array}{l}\text { Igor Braga } \\
\text { Farias, MD }\end{array}$ & $\begin{array}{l}\text { Federal } \\
\text { University of } \\
\text { São Paulo } \\
\text { (UNIFESP), } \\
\text { Brazil }\end{array}$ & Author & $\begin{array}{l}\text { Case report project } \\
\text { (conception, } \\
\text { organization, } \\
\text { execution), writing } \\
\text { of the first draft, } \\
\text { review and critique }\end{array}$ \\
\hline $\begin{array}{l}\text { Eduardo } \\
\text { Augusto } \\
\text { Gonçalves, } \\
\text { MD }\end{array}$ & $\begin{array}{l}\text { Federal } \\
\text { University of } \\
\text { São Paulo } \\
\text { (UNIFESP), } \\
\text { Brazil }\end{array}$ & Author & $\begin{array}{l}\text { Case report project } \\
\text { (conception, } \\
\text { organization, } \\
\text { execution), writing } \\
\text { of the first draft, } \\
\text { review and critique }\end{array}$ \\
\hline $\begin{array}{l}\text { Bruno de } \\
\text { Mattos } \\
\text { Lombardi } \\
\text { Badia, MD }\end{array}$ & $\begin{array}{l}\text { Federal } \\
\text { University of } \\
\text { São Paulo } \\
\text { (UNIFESP), } \\
\text { Brazil }\end{array}$ & Author & $\begin{array}{l}\text { Case report project } \\
\text { (conception, } \\
\text { organization, } \\
\text { execution), writing } \\
\text { of the first draft, } \\
\text { review and critique }\end{array}$ \\
\hline
\end{tabular}

Appendix (continued)

\begin{tabular}{|c|c|c|c|}
\hline Name & Location & Role & Contribution \\
\hline $\begin{array}{l}\text { Luiz } \\
\text { Henrique } \\
\text { Libardi Silva, } \\
\text { MD }\end{array}$ & $\begin{array}{l}\text { Federal } \\
\text { University of } \\
\text { São Paulo } \\
\text { (UNIFESP), } \\
\text { Brazil }\end{array}$ & Author & $\begin{array}{l}\text { Case report project } \\
\text { (conception, } \\
\text { organization, } \\
\text { execution), writing } \\
\text { of the first draft, } \\
\text { review and critique }\end{array}$ \\
\hline $\begin{array}{l}\text { Mario Teruo } \\
\text { Yanagiura, } \\
\text { MD }\end{array}$ & $\begin{array}{l}\text { Federal } \\
\text { University of } \\
\text { São Paulo } \\
\text { (UNIFESP), } \\
\text { Brazil }\end{array}$ & Author & $\begin{array}{l}\text { Case report project } \\
\text { (conception, } \\
\text { organization, } \\
\text { execution), writing } \\
\text { of the first draft, } \\
\text { review and critique }\end{array}$ \\
\hline $\begin{array}{l}\text { Wladimir } \\
\text { Bocca Vieira } \\
\text { de Rezende } \\
\text { Pinto, MD, } \\
\text { MSc }\end{array}$ & $\begin{array}{l}\text { Federal } \\
\text { University of } \\
\text { São Paulo } \\
\text { (UNIFESP), } \\
\text { Brazil }\end{array}$ & $\begin{array}{l}\text { Corresponding } \\
\text { author }\end{array}$ & $\begin{array}{l}\text { Case report project } \\
\text { (conception, } \\
\text { organization, } \\
\text { execution), writing } \\
\text { of the first draft, } \\
\text { review and critique }\end{array}$ \\
\hline $\begin{array}{l}\text { Acary Souza } \\
\text { Bulle } \\
\text { Oliveira, MD, } \\
\text { PhD }\end{array}$ & $\begin{array}{l}\text { Federal } \\
\text { University of } \\
\text { São Paulo } \\
\text { (UNIFESP), } \\
\text { Brazil }\end{array}$ & Author & $\begin{array}{l}\text { Case report project } \\
\text { (conception), review } \\
\text { and critique }\end{array}$ \\
\hline
\end{tabular}

\section{References}

1. Liedholm LJ, Eeg-Olofsson O, Ekenberg BE, Nicolaysen RB, Torbergsen T. Acute postasthmatic amyotrophy (Hopkins' syndrome). Muscle Nerve 1994;17:769-772.

2. Hayashi F, Hayashi S, Matsuse D, Yamasaki R, Yonekura K, Kira JI. Hopkins syndrome following the first episode of bronchial asthma associated with enterovirus D68: a case report. BMC Neurol 2018;18:71. 


\section{Neurology}

\section{Teaching NeuroImages: Hopkins syndrome: A rare differential diagnosis of neurogenic monomelic amyotrophy}

Paulo Victor Sgobbi de Souza, Bruno de Mattos Lombardi Badia, Eduardo Augusto

Gonçalves, et al.

Neurology 2020;94;e996-e997 Published Online before print February 10, 2020

DOI 10.1212/WNL.0000000000009038

This information is current as of February 10, 2020

\section{Updated Information \&} Services

References

Subspecialty Collections

Permissions \& Licensing

Reprints including high resolution figures, can be found at: http://n.neurology.org/content/94/9/e996.full

This article cites 2 articles, 0 of which you can access for free at: http://n.neurology.org/content/94/9/e996.full\#ref-list-1

This article, along with others on similar topics, appears in the following collection(s):

\section{Anterior nerve cell disease}

http://n.neurology.org/cgi/collection/anterior_nerve_cell_disease

Information about reproducing this article in parts (figures,tables) or in its entirety can be found online at:

http://www.neurology.org/about/about_the_journal\#permissions

Information about ordering reprints can be found online:

http://n.neurology.org/subscribers/advertise

Neurology ${ }^{\circledR}$ is the official journal of the American Academy of Neurology. Published continuously since 1951, it is now a weekly with 48 issues per year. Copyright @ 2020 American Academy of Neurology. All rights reserved. Print ISSN: 0028-3878. Online ISSN: 1526-632X.

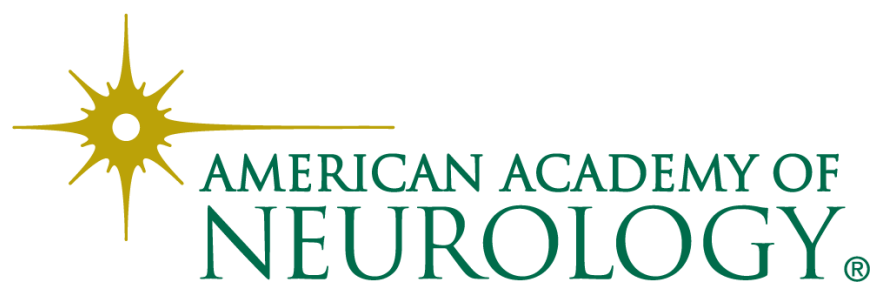

